\title{
КОЛИЧЕСТВЕННОЕ ИЗМЕРЕНИЕ МЕЖДУНАРОДНОЙ ЭНЕРГЕТИЧЕСКОЙ БЕЗОПАСНОСТИ
}

\begin{abstract}
Аннотация: Статья посвящена выработке методики количественного измерения международной энергетической безопасности. Указывается, что для достоверной оченки энергобезопасности государства его энергетическая система должна быть равномерно рассмотрена с разных перспектив (экономической, политической, социальной, экологической, с точки зрения национальной безопасности, международных соглашений и обязательств), включая весь комплекс её составных элементов. Оиенка энергетической безопасности должна быть характеристикой качества проводимой национальной энергетической политики. Выделены основные свойства, которыми должна обладать такая оценка. В работе рассмотрены существующие методы количественной оценки энергобезопасности государств, выявлены их основные достоинства и недостатки. Основываясь на проведенном анализе, была разработана методика комплексной оиенки международной энергобезопасности (КОМЭБ). Оченка складывается из 21 индикатора энергетической безопасности в четырех взаимосвязанных измерениях: экономическом, технологическом, социально-политическом и экологическом. После описания методики составления оценки осуществляется сопоставительный анализ основных количественных способов оценки энергетической безопасности с указанием отличительных особенностей КОМЭБ. Так, КОМЭБ служит полезным индикатором общего состояния всех областей энергетической системы страны. На её основе можно ретроспективно проанализировать имплементацию мер по обеспечению энергобезопасности страны, равно как и спрогнозировать эффект от реализации разрабатываемых и принятых энергетических стратегий. Кроме того, такая оценка позволяет сравнить уровни энергобезопасности в разных странах и, в сочетании с анализом успешных практик, модифицировать национальные энергетические стратегии. Наконеи, на основе полученных данных о состоянии энергобезопасности в соседних странах, облегчаются условия регионального и международного энергетического сотрудничества и кооперации.
\end{abstract}

Review: The article is devoted to the development of methodology for the quantitative dimension of the international security of energy supply. It is noted that in order to accurately evaluate energy security of the state, its energy system should be equally evaluated from the various perspectives (economic, political, social, environmental, national security, international obligations and treaties), including an entire complex of its components. Energy security evaluation should characterize the quality of the national energy policy. The article contains analysis of the characteristic features which such an evaluation should possess. The author singles out the key methods for the quantitative dimension of the energy security of the state as well as their strong and weak points. Based upon the above-mentioned analysis the method for the complex evaluation of international energy security (CEIES) was formed. Evaluation includes 21 indicators of energy security in 4 interrelated dimensions: economic, technological, socialpolitical and environmental. In addition to the description of the method the article includes comparative analysis of the key quantitative methods for the energy security evaluation with the specific features of CEIES being pointed out. For example, CEIES serves as an useful indicator for the general condition of all of the spheres of energy security within the state. Based on it one can provide retrospective analysis of implementation of measures aimed to guarantee energy security of the state, as well as predict the efficiency of implementation of current and newly developed energy strategies. Additionally, such an 
evaluation allows to compare the levels of energy security in different sates and to modify the national energy strategies based on the analysis of successful practices. Finally, based upon the data on energy security in the neighboring states, one may ease the conditions for regional and international energy cooperation.

Ключевые слова: обеспечение безопасности, энергетическая стратегия, начиональная безопасность, энергосистема, сравнительная политология, энергетическая политика, количественные исследования, энергетическая безопасность, государственное управление, международная политика Keywords: security guarantees, energy strategy, national security, energy system, comparative political science, energy policy, quantitative studies, energy security, state administration, international politics.

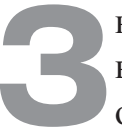
начительная часть существующих исследований опирается на неполное или нечеткое определение энергетической безопасности (ЭнБ), при этом в центре внимания оказываются отдельные, довольно узкие экономические или технологические вопросы, к примеру, обеспечение безопасности импорта углеводородных энергоресурсов, субсидирование конечных пользователей или инвестиции в энергетическую инфраструктуру. В то же время за горизонтом внимания исследователей до последнего времени оставались не менее важные социальные и политические элементы, такие как вопросы качества государственного регулирования энергетических систем и многие другие.

Как отмечает Б. Совакул, во многих исследованиях ЭнБ рассматриваются либо отдельные сектора (транспортный, промышленный), либо отдельные страны, либо отдельные элементы энергетического баланса (обеспечение нефтяной или ядерной безопасности) ${ }^{1}$. Сравнение и сопоставление измерений ЭнБ, относительная сила и слабость отдельных подходов к ее измерению, попытки количественно оценить качество государственной политики по обеспечению ЭнБ оставались недостаточно разработанными исследовательскими направлениями. Возможно, это объясняется отсутствием консенсуса как по самому понятию ЭнБ, так и по отдельным его структурным элементам. В этой связи совершенно не удивляют периодические ссылки на то, что понятие ЭнБ является абстрактным, неопределенным, расплывчатым и даже внутренне противоречивым ${ }^{2}$.

\footnotetext{
${ }^{1}$ Sovacool, B.K. An international assessment of energy security performance. Ecological Economics, 88, 2013, p. 149.

${ }^{2}$ Alhajji, A.F. The meaning of energy security. Блог USAEE, 2006, 22 августа.

Loschel, A., Moslener, U., Rubbelke, D. Indicators of energy security in industrialized countries. Energy Policy, 37, 2009 и др.
}

Для достоверной оценки ЭнБ государства, его энергетическая система должна быть равномерно рассмотрена с разных перспектив (экономической, политической, социальной, экологической, с точки зрения национальной безопасности, международных соглашений и обязательств), включая самые разные ее составляющие, от добычи до конечного использования, включая переработку, транспортировку, то, насколько эффективно существующая энергосистема работает относительно других, ей подобных.

В настоящее время предложено несколько методов количественной оценки ЭнБ государств, причем как национальными научными институтами и отдельными исследователями, так и международными организациями. Мы рассмотрим “индекс спроса и предложения”, разработанный Центром энергетических исследований Нидерландов, разработки Международного энергетического агентства, Мирового энергетического совета, Центра энергетики XXI века (при Торговой палате США) и некоторые другие. При этом основное внимание будет уделено агрегированным (представляющим собой совокупность более простых) индикаторам, определяющим и оценивающим ЭнБ на национальном уровне, с возможностью межстранового сопоставления. Такие индикаторы показывают, насколько успешно правительствам разных государств удается увязывать вопросы функционирования и развития энергосистем с широким кругом политических, экономических, экологических и социальных задач, стоящих перед обществом.

На основе рассмотренных способов анализа и оценки ЭнБ будет предложена рамочная структура комплексной оценки международной ЭнБ (КОМЭБ).

Ценность подобного подхода заключается в нескольких аспектах.

- Во-первых, рассмотрение ЭнБ как комплексной системы, состоящей из нескольких связанных 


\section{Национальная безопасность 4(27) • 2013}

измерений, регулируемой средствами государственной энергетической политики, позволяет уйти от узкого понимания ЭнБ как обеспечения безопасности исключительно спроса или предложения, безопасности поставок отдельных видов топлива или фокуса на ценовой конъюнктуре. Важно понимать, что энергетические рынки являются "продуктом сложных процессов социального и исторического развития", с ключевой ролью государственной политики (как внутренней, так и внешней) разных стран и межправительственных соглашений в их организации, функционировании и регулировании.

- Во-вторых, комплексная оценка состояния ЭнБ может служить показателем качества энергетической политики государства. Текущее состояние ЭнБ является продуктом прежней и зависит от нынешней национальной энергетической политики, соответственно, комплексный показатель такого состояния демонстрирует, как изменение в регулировании даже отдельного элемента энергетической системы влияет на состояние всей системы в целом.

- В-третьих, индекс предоставляет возможность пространственных и временных сопоставлений. Изменение индекса в разные временные периоды может свидетельствовать о том, как на обеспечение ЭнБ влияли внешние (военные конфликты, значительные колебания цен или ограничение поставок по не зависящим от страны обстоятельствам) и внутренние (природные катаклизмы, изменение энергетической политики, технологические достижения) макроэкономические или политические события и процессы. Единая методология расчета индекса, в свою очередь, предоставляет возможность межстрановых сопоставлений эффективности национальных энергетических политик в сходных по положению в мировой энергетической системе государств.

- В-четвертых, индекс выявляет связи между измерениями ЭнБ, уязвимые места, требующие изменения регулирования, и в то же время позволяет показать, как изменения в одной области влияют на другие (например, отмена субсидирования потребления электроэнергии домохозяйствами может повысить энергоэффективность,

\footnotetext{
${ }^{3}$ Chester $L$. Conceptualizing energy security and making explicit its polysemic nature. Energy Policy, 38, 2010, pp. 887-895.
}

но одновременно ухудшает её доступность для населения) и на обеспечение ЭнБ в целом ${ }^{4}$.

- В-пятых, методологическая гибкость комплексной оценки ЭнБ позволяет без существенной переработки адаптировать ее под разные исследовательские и прогностические задачи. Так, при изменении акцентов энергетической политики (например, при изменении налогообложения с целью стимулировать рост качества переработки нефти), или принятии новых обязательств в рамках международных соглашений, при существенном изменении состояния энергетической системы достаточно изменить отдельные относительные значения категорий (индикаторных блоков) внутри рейтинга в соответствии с изменением их приоритетности для проведения политики или её анализа. При этом структура рейтинга сохраняет свою целостность.

\section{Обзор существующих количественных подходов к оценке ЭнБ}

Рассмотрим некоторые из растущего множества работ, посвященных определению и квантификации ЭнБ государств. При этом важно понимать не только методологию таких исследований, но и их “идеологию”, набор представлений о безопасности энергетической системы отдельных стран и мировой энергетической системы в целом. В конечном счете, он не только определяет набор исходных данных, аналитических инструментов для их переработки, но и обуславливает полученные результаты. По результатам анализа появится возможность сопоставить сущностные характеристики, общие недостатки и ограничения рассмотренных подходов с методикой оценки ЭнБ, которая представлена в настоящей работе.

Основываясь на работе Вон Хиппеля 5 , в которой рассматриваются шесть основных измерений ЭнБ (наряду с традиционными измерениями, отдельно выделяются социокультурное и военно-стратегическое измерения), Владо Вывода добавляет еще пять дополнительных измерений, включающих 44 характеристики глобальной энергосистемы, релевантные для анализа ЭнБ ${ }^{6}$. Некоторые из них прежде вовсе не

\footnotetext{
${ }^{4}$ B.K. Sovacool, 2013. Ibid., p. 149.

${ }^{5}$ Von Hippel, D. et al. Energy security and sustainability in Northeast Asia. Energy Policy, 1-12, 2009.

${ }^{6}$ Vivoda $V$. Evaluating energy security in the Asia-Pacific region: a
} 
рассматривались исследователями в таком контексте. Так, исследователь обратил внимание на то, что обеспечение ЭнБ отдельных государств в современном мире реализуется и зависит от межгосударственного взаимодействия как на экономическом, так и на политическом, социальном и многих других уровнях. Следовательно, возможно выделить отдельно международное измерение ЭнБ, которое оценивает степень включенности страны в повестку дня международных энергетических отношений (оценивается участие страны в региональных и международных структурах, координирующих усилия в области ЭнБ, участие в международных соглашениях, посвященных энергетическим вопросам). В соответствии с теоретиками международных отношений Кеохейном и Наем$^{7}$, предполагается, что в условиях глобализации, роста числа акторов на международных энергетических рынках, усложнении энергетических систем, общих для всех участников негативных экологических экстерналий (будь то глобальное изменение климата, опасность региональных катастроф в ходе добычи нефти или аварий на ядерных электростанциях и др.), страны становятся более склонны развивать международные институты, снижать транзакционные издержки через установление стабильных правил игры на энергетических рынках.

Кроме того, в качестве отдельного аспекта выделяется принципиальное наличие и практика реализации в стране доктрины ЭнБ. Обращается внимание на то, насколько в такой стратегии учитываются другие измерения ЭнБ, связи между ними, а также регулярность обновления и пересмотра этой доктрины (место, которое она занимает в политической повестке дня). Интересно, что в октябре 2012 года на необходимость утверждения такой доктрины для России обратил внимание президент Владимир Путин $^{8}$ (поручение ее разработать отдал еще прежний президент Дмитрий Медведев в конце 2010 г.).

Следует заметить, что предлагаемый инструмент сложно назвать универсально применимым, поскольку он требует качественных оценок таких параметров, как, например, “уязвимость критически важных объектов энергетической инфраструктуры к рискам национальной безопасности (терроризм, ресурсные

novel methodological approach, Energy Policy, 38, 2010.

${ }^{7}$ Keohane, R.O., Nye, J.S. Power and interdependence. Longman, New York, 2001.

8 Латухина К. Во глубине ямальских недр // Российская газета. -2012, 24 октября. конфликты, пиратство, распространение ядерного оружия)" или “прозрачность доктрины национальной ЭнБ”. Такие оценки явно будут обладать ограниченной объективностью и их сложно осуществлять для большого числа государств, однако они могут быть весьма полезны при анализе ЭнБ небольшого числа стран (выделенных по территориальному принципу или в силу членства в определенной организации).

В разное время количественным измерением ЭнБ занимались влиятельные энергетические организации, включая международные. В частности, МАГАТЭ предложило набор из 30 индикаторов, охватывающих социальное, экономическое и экологическое измерения ${ }^{9}$. МА разработал показатель “геополитической ЭнБ”, комбинирующий политический риск в стране-поставщике энергоресурсов, долю каждого поставщика в балансе поставок ископаемого сырья, предложение на доступных покупателю рынках основных видов топлива (уголь, нефть и газ), в зависимости от структуры энергобаланса конкретной страны ${ }^{10}$.

Кроме того, Агентством были предложены два индикатора, характеризующие ценовой аспект ЭнБ и компоненту физической доступности энергоресурсов $^{11}$. Первый из них, отвечающий за физическую доступность, является нарочито политически мотивированным и измеряется как доля в совокупном энергобалансе природного газа, поставляемого через трубопроводные системы по долгосрочным контрактам с ценами, привязанными к нефтяным котировкам. Другими словами, чем больше та или иная европейская страна зависит от поставок природного газа из России, тем менее в ней обеспечена ЭнБ.

Другой индикатор оценивает ценовые риски зависимости от поставщиков отдельных энергоресурсов через адаптированный индекс концентрации Хирфиндаля-Хиршмана. Индикатор включает уже упомянутую компоненту политической стабильности, что задает сниженный уровень объективности показателя, а также основан на твердой вере в способность либерализованных энергетических рынков к самоорганизации.

\footnotetext{
${ }^{9}$ International Atomic Energy Agency. Energy indicators for sustainable development: guidelines and methodologies. IAEA, Vienna, 2005.

${ }^{10}$ Blyth W., Lefevre N. Energy security and climate change policy interactions: an assessment framework. International Energy Agency (IEA), 2004.

${ }^{11}$ International Energy Agency. Energy security and climate policy assessing, interactions. IEA, Paris, 2007.
} 


\section{Национальная безопасность 4(27) • 2013}

Центр энергетических исследований Нидерландов разработал комплексный “индекс спроса и предложения”, в котором, наряду с предсказуемой оценкой диверсификации энергобаланса (поставок из отдельных стран, взвешенных по политическому риску), дается оценка структуры и объема спроса на энергетические услуги в стране, рассматривается эластичность предложения для различных категорий этих услуг, внутренняя производственная цепочка, мощности переработки, транспортировки и хранения энергоресурсов. Индекс основан на экспертных оценках соответствующих показателей. Однако, несмотря на введение в индекс показателей безопасности внутреннего состояния энергосистем, он оставался нацеленным на узкий сегмент европейских странимпортеров энергоресурсов.

Мировой Энергетический Совет (МИРЭС) для оценки того, насколько странам-членам этой организации удается обеспечить стабильное функционирование энергосистем с учетом ценовых и экологических факторов, использует составной показатель “энергетической устойчивости”'12. Он состоит из 22 индикаторов, объединенных в 4 блока:

1. Энергетическая безопасность (в узком понимании). Сюда, в частности, входят показатели отношения производства энергоресурсов к потреблению, разнородность энергобаланса, рост потребления энергоресурсов, оптовая надбавка на бензин. В этом блоке присутствует единственное зафиксированное в методологии работы различие в оценке ЭнБ экспортеров и импортеров: у первых измеряется диверсифицированность экспорта энергоресурсов, в то время как у вторых - объем стратегических нефтяных резервов.

2. Социальная справедливость

Оценивается простым сравнением средней стоимости бензина и электричества для розничных покупателей в разных странах.

3. Воздействие на окружающую среду

Для измерения используют показатели энергетической и эмиссионной интенсивности, загрязнение воздуха и воды.

4. Качество государственного управления и социально-экономической структуры

Включает напрямую не связанные с энергетикой показатели общей эффективности государственной политики, измеряемые с помощью широкого

${ }^{12}$ World Energy Council. World energy trilemma. Energy sustainability index. WEC, London, 2012. набора политических, общественных и экономических индикаторов, предлагаемых Всемирным банком и Всемирным экономическим форумом. При этом страны группируются не только по характеру участия в мировой энергосистеме (импортер/экспортер), но и по уровню экономического развития. Выделены четыре группы стран по уровню ВВП на душу населения (по ППС): выше 33,5 тыс. долл. США (группа А), от 14,3 до 33,5 (группа В), от 6 до 14,3 (C) и с уровнем подушевого ВВП ниже 6 тыс. долл. США (D). Оправданность подобной кластеризации стран по сопоставимости их социально-экономических и энергосистем подтверждается недавним исследованием Дж. Нокс-Хейес ${ }^{13}$, в котором была обнаружена корреляция между уровнем экономического развития в отдельных странах и восприятием угроз ЭнБ респондентами.

Наряду с очевидно суженным пониманием ЭнБ, невооруженным взглядом заметен выборочный характер используемых индикаторов, с помощью которых невозможно дать полноценную оценку ЭнБ отдельных стран. Декларируемое равное влияние на итоговую оценку разных индикаторных блоков на практике приводит к тому, что относительно большее значение имеют отдельные индикаторы в минимальных по объему индикаторных блоках (во втором блоке индикаторы в 2,5 раза более значимы, чем в первом, и в 4,5 раза более значимы, чем любой из индикаторов четвертого блока). Этот факт, наряду с тем, что методика подсчета отдельных показателей является непрозрачной (известны лишь данные "на входе" и “на выходе" - методика сведения данных в индекс не раскрывается), приводит к парадоксальным результатам. Так, показатель “доступности бензина в рознице” призван распределить страны по стоимости бензина, которая зафиксирована в среднем за период в этих странах на ценниках автозаправочных станций. При таком подсчете наилучшая ситуация должна ожидаться в крупных странах-экспортерах, традиционно субсидирующих розничное потребление топлива, - в Саудовской Аравии, ОАЭ, Индонезии, Иране. Ничего подобного не происходит. За максимальное значение принимается стоимость топлива в США (то же касается и стоимости электроэнергии), а расхождения в обе стороны штрафуются снятием баллов.

\footnotetext{
${ }^{13}$ Knox-Hayes, $J$. et al. Understanding attitudes toward energy security: results of a cross-national survey. Global Environmental Change, 23, 2013, p. 610.
} 
Подобного не позволяли себе исследователи Института энергетики XXI века Торговой палаты США. В 2012 году ими был представлен индекс международной энергетической безопасности, нацеленный на оценку страновых рисков на международном энергетическом рынке. По сравнению с Индексом рисков ЭнБ США, выпущенным в 2010 году и послужившим основой расчетов межстрановой оценки ЭнБ, методология работы подверглась определенным изменениям. Прежний индекс состоял из 37 показателей, объединенных в 9 категорий, составлявших 4 измерения ЭнБ США: геополитическое (30\% общей оценки), экономическое (30\%), технологическое (субиндекс надежности энергосистем, 20\%) и экологическое (20\%). При этом каждый из отдельных показателей мог быть частью как одного (индикатор “розничных цен на электроэнергию” полностью входит в экономическое измерение, составляя $10 \%$ его оценки и 3\% общего показателя ЭнБ страны), так и нескольких (индикатор “затрат на импорт ископаемого топлива” составляет $6 \%$ геополитического и экономического измерений или $3,6 \%$ общего показателя) измерений ЭнБ. Ограниченность и нехватка необходимой информации и статистических данных по сравнению с глубоко детализированной энергетической статистикой в США вынудила авторов сократить число используемых показателей до 28 и отказаться от разделения совокупного странового Индекса ЭнБ на отдельные измерения. Отдельные показатели напрямую составляют определенный процент итогового индекса, получаемый на основе экспертных оценок ${ }^{14}$.

Недостатки такого подхода являются производными от его методологии. Для того, чтобы оценки ЭнБ разных стран можно было сопоставить друг с другом и во времени, все значения индикаторов были нормированы по отношению к среднему показателю в странах ОЭСР в 1980 году. Однако, несмотря на то, что в числе таких государств представлены такие крупные страны-экспортеры, как Канада или Австралия, включенные в организацию государства в основном представляют крупнейшие развитые страны-импортеры энергоресурсов. Но и в этом случае подобный выбор стран со временем все менее оправдан: если в 1980-е годы на организацию приходилось $63 \%$ мирового потребления

14 Так, показатель “энергоинтенсивности экономики” (объем потребленной первичной энергии на единицу реального ВВП) дает 7\% итоговой оценки, а показатель “зависимости от импорта природного газа"- $2 \%$. энергии, то в 2000-е совокупная доля упала ниже $50 \%$. При этом долее 90\% прироста потребления приходится на новые центры спроса (в их числе Индия, Китай и страны Юго-восточной Азии). Кроме того, за более чем 30 лет существенно изменилась структура мировой энергетической системы, так что спорной оказывается базовая методологическая основа работы.

Несмотря на безусловную ценность представленных подходов к количественной оценке ЭнБ на государственном уровне, многие из них и некоторые другие страдают от ряда общих недостатков.

Большинство исследований специально разработаны или сфокусированы на промышленно развитых странах-импортерах, в основном входящих в ОЭСР. Такие работы часто исходят из принципиально не применимого для анализа мировой ЭнБ восприятия ЭнБ как, например, “доступности энергии для тех, кто готов заплатить за неё рыночную цену”. Подобные подходы неприменимы для анализа ЭнБ развивающихся и менее развитых государств, где население часто не имеет полноценного доступа к электроэнергии, моторизированному транспорту и использует органическое топливо для обогрева жилищ. С другой стороны, упомянутые исследования МАГАТЭ и МЭА оценивают скорее устойчивое развитие и энергетическую бедность, чем ЭнБ в целом.

Многие показатели ЭнБ разработаны для отдельных секторов энергетической системы (электроэнергетика, нефтяной или газовый сектор) и ориентированы на безопасность поставок энергоресурсов, пренебрегая тем, что происходит с импортируемыми энергоресурсами после пересечения национальных границ ${ }^{15}$. Часто игнорируются геополитические связи, технологическое и экологические измерения. К примеру, это касается упомянутого "Индекса спроса и предложения", в котором в основном рассматривается экономическое измерение ЭнБ. Это приводит к дисбалансу итоговых показателей. Так, МАГАТЭ использует 16 “экономических” и только 4 “социальных" индикатора ЭнБ. Мартчамадол и Кумар провели анализ существующих индикаторов ЭнБ, используемых при анализе ее проблем. При их распределении оказалось, что экологических индикаторов 8 , социальных -7 , институциональных -11 (в основном, это предлагаемые Всемирным Банком и Всемирным экономическим форумом раз-

\footnotetext{
${ }^{15}$ B.K. Sovacool, 2013. Ibid.
} 


\section{Национальная безопасность 4(27) • 2013}

нообразные индикаторы качества госуправления). Экономических же отдельными исследователями и организациями используется $68^{16}$.

Как правило, международные или правительственные организации предоставляют только общую информацию о методологии моделей и индексов ЭнБ. Такие работы часто страдают от недостатка транспарентности при сведении отдельных показателей в общий индекс. Как в случае с индексом "розничных цен на топливо" в работе МИРЭС, только по косвенным признакам можно судить о том, как определяются конкретные значения отдельных индикаторов ЭнБ.

Другая важная проблема, стоящая перед любым исследователем количественных аспектов ЭнБ - критический недостаток релевантной информации для анализа ЭнБ в разных странах. В частности, для расчета индекса рыночных цен на электроэнергию, объема энергетических субсидий во многих странах Африки и Азии вместо отсутствующих статистических данных необходимо использовать не всегда прозрачные и всегда неточные экспертные оценки.

На основе проведенного анализа существующих количественных способов измерения ЭнБ можно уточнить необходимые характеристики предлагаемой комплексной оценки международной ЭнБ (КОМЭБ). Она должна служить полезным индикатором общего состояния всех областей энергетической системы страны. На её основе можно ретроспективно проанализировать имплементацию мер по обеспечению ЭнБ страны, равно как и спрогнозировать эффект от реализации разрабатываемых и принятых национальных энергетических стратегий ${ }^{17}$. Этим КОМЭБ способствует учету прошлого опыта и совершенствованию таких стратегий. Кроме того, такая оценка позволяет сравнить уровни ЭнБ в разных странах и, в сочетании с анализом успешных практик, модифицировать энергетические стратегии. Наконец, на основе полученных данных о состоянии ЭнБ в соседних странах, облегчаются условия регионального и международного энергетического сотрудничества и кооперации.

\footnotetext{
${ }^{16}$ Martchamadol J, Kumar S. An aggregated energy security performance indicator. Applied Energy, vol. 103, 2013, pp. 653-670.

17 КОМЭБ может использоваться как составляющая базового сценария национальной энергетической политики. Эффективность такой политики определяется как изменение фактических показателей индикатора по отношению к запланированным.
}

\section{Конструирование комплексной оценки международной энергетической безопасности}

На основе рассмотрения широкого массива литературы по количественной оценке ЭнБ, включая национальные энергетические программы и концепции, документы и материалы исследовательских институтов и международных организаций, была разработана методика комплексной оценки международной ЭнБ (КОМЭБ). При этом за основу были приняты обозначенные выше требования к подобной оценке.

Энергетическая безопасность рассматривалась как реализуемое средствами внешней и внутренней национальной энергетической политики функционирование энергосистемы, обеспечивающее долгосрочное устойчивое развитие социально-экономической системы страны. Соответственно, оценка ЭнБ является характеристикой качества проводимой национальной энергетической политики.

Для целей исследования были адаптированы существующие или заново созданы 21 индикатор ЭнБ в четырех измерениях: экономическом (6 индикаторов), технологическом (измерении технологической эффективности - 5), социально-политическом (6) и экологическом (измерении влияния энергетической системы на окружающую среду - 4). При этом методологической задачей было охватить все измерения и сектора энергетической системы минимальным по количеству и максимально интуитивно понятными и прозрачными индикаторами. Важным и отличительным от других упомянутых методов было обеспечить связь между измерениями, не усложняя расчет оценки. До этого связность измерений обеспечивалась с помощью математического и эконометрического моделирования, чрезмерно усложняющих и затрудняющих понимание модели ${ }^{18}$, в КОМЭБ эта цель достигается с помощью взаимопереплетенности индикаторов. Отдельные индикаторы определяют, какие из общего набора индикаторов во всех измерениях будут применяться для анализа ЭнБ конкретной страны. Кроме того, индикаторы из одних измерений ЭнБ участвуют в расчете значений других, подтверждая необходимость учитывать, как и насколько серьезно меры национальной энергетической политики в отдельной области повлияют на состояние

\footnotetext{
${ }^{18}$ Martchamadol J, Kumar S., 2012. Ibid.;

Shin, J. et al. An energy security management model using quality function deployment and system dynamics. Energy Policy, 2012 и др.
} 
безопасности всей национальной энергетической системы. Все индикаторы КОМЭБ, принадлежащие отдельным измерениям ЭнБ, подробно рассмотрены в таблице 1.

После расчета индикаторов полученные значения при необходимости инвертируются так, чтобы более высокое значение индикаторов однозначно соответствовало более высокой обеспеченности ЭнБ (например, показатели Э5и, Т1, Т2, Т4 и другие, цель - облегчение восприятия значений индикаторов). После этого отдельные оценки индикаторов нормируются по наиболее высокому показателю в соответствующем им кластерном блоке (положение страны в нем определяется ролью страны в международной энергетической системе и степенью экономического развития страны ${ }^{19}$ ) и принимают значения от 0 до 100. Далее оценки суммируются по измерениям ЭнБ, и в соответствии с указанными весами измерений определяется итоговое значение КОМЭБ в диапазоне от 0 до 100 (максимум). Предположительные веса отдельных измерений ЭнБ указаны в таблице 1 , однако при различных исследовательских приоритетах или существенном изменении конъюнктуры мировой энергосистемы они легко могут быть изменены, не нарушая целостности КОМЭБ.

Таблиияа 1. Измерения и индикаторы КОМЭБ

\begin{tabular}{|c|c|c|c|}
\hline $\begin{array}{l}\text { Измере- } \\
\text { ние }\end{array}$ & \multicolumn{2}{|c|}{ Индикатор } & Расчет индикатора и единицы измерения \\
\hline \multirow{6}{*}{ 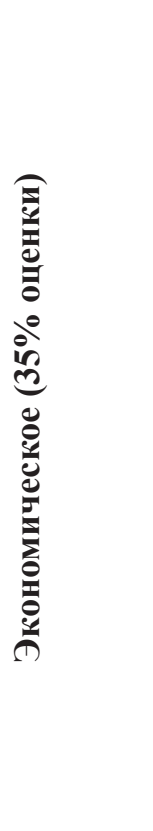 } & \multicolumn{2}{|c|}{$\begin{array}{l}\text { Э1. Обеспеченность энер- } \\
\text { гией }\end{array}$} & $\begin{array}{l}\text { Отношение энергии, произведенной в стране, к потребленной } \\
\text { за период, \%. Индикатор определяет, является страна нетто- } \\
\text { экспортером или импортером энергоресурсов }\end{array}$ \\
\hline & \multicolumn{2}{|c|}{$\begin{array}{l}\text { Э2. Безопасность производ- } \\
\text { ства }\end{array}$} & $\begin{array}{l}\text { Среднее отношение запасов к производству основных ископае- } \\
\text { мых видов топлива (уголь, природный газ, нефть), взвешенное } \\
\text { по объему в Первичном энергобалансе (ПЭ), оставшихся лет } \\
\text { производства }\end{array}$ \\
\hline & \multicolumn{2}{|c|}{$\begin{array}{l}\text { Э3. Диверсификация элек- } \\
\text { трогенерации }\end{array}$} & $\begin{array}{l}\text { Индекс Шеннона-Вайнера, характеризующий распределен- } \\
\text { ность электрогенерации в стране, от } 0 \text { до 1(макс). }\end{array}$ \\
\hline & \multicolumn{2}{|c|}{$\begin{array}{l}\text { Э4. Диверсификация источ- } \\
\text { ников энергии }\end{array}$} & $\begin{array}{l}\text { Индекс Шеннона-Вайнера, характеризующий распределен- } \\
\text { ность источников энергии в ПЭ страны, от } 0 \text { до 1(макс). }\end{array}$ \\
\hline & $\begin{array}{l}\text { Для импор- } \\
\text { теров }\end{array}$ & $\begin{array}{l}\text { Э5и. Импорто- } \\
\text { зависимость }\end{array}$ & Отношение импорта энергоресурсов к объему ВВП, \% \\
\hline & $\begin{array}{l}\text { Для экс- } \\
\text { портеров }\end{array}$ & $\begin{array}{l}\text { Э5э. Зависи- } \\
\text { мость от экс- } \\
\text { порта }\end{array}$ & $\begin{array}{l}\text { Отношение экспорта энергоресурсов к общему объему экспор- } \\
\text { та страны, \% }\end{array}$ \\
\hline
\end{tabular}

\footnotetext{
19 Этим снимается проблема “сравнения яблок и апельсинов”. Сорман и Джампьетро показали обманчивую природу некоторых показателей, которая может затруднять анализ энергополитики разных стран. Так, энергоинтенсивность экономик Сальвадора и Финляндии, стран разных энергетических миров, в целом сопоставима. С помощью декомпозиции индикатора было показано, что на единицу человеческой работы Сальвадор потребляет на порядок меньше энергии, в то время как экономическая эффективность труда в Финляндии выше на тот же порядок. См. Sorman A.H., Giampietro M. Generating better energy indicators: addressing the existence of multiple scales and multiple dimensions. Ecological Modelling, 223, 2011.
} 
DOI: $10.7256 / 2073-8560.2013 .4 .8897$

При цитировании этой статьи сноска на dоі обязательна

\section{Национальная безопасность 4(27) • 2013}

\begin{tabular}{|c|c|c|c|}
\hline \multirow{5}{*}{ 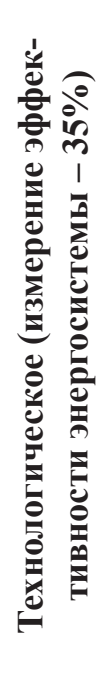 } & \multicolumn{2}{|c|}{ Т1. Энергетическая эффективность } & Объем потребленной энергии на душу населения в стране, тнэ \\
\hline & \multicolumn{2}{|c|}{ Т2. Эффективность электросетей } & $\begin{array}{l}\text { Процент потерь при передаче и распределении электро- } \\
\text { энергии от производителей до конечных потребителей, } \\
\text { включая несанкционированное подключение к сетям }\end{array}$ \\
\hline & \multicolumn{2}{|c|}{$\begin{array}{l}\text { Т3. Эффективность переработки } \\
\text { энергии }\end{array}$} & $\begin{array}{l}\text { Отношение конечного потребления энергоресурсов к раз- } \\
\text { нице между ПЭ и суммой затрат энергии на переработку } \\
\text { энергоресурсов и собственного потребления перерабаты- } \\
\text { вающего сектора, \% }\end{array}$ \\
\hline & \multicolumn{2}{|c|}{$\begin{array}{l}\text { Т4. Эффективность транспортного } \\
\text { сектора }\end{array}$} & $\begin{array}{l}\text { Конечное потребление энергии транспортным сектором } \\
\text { на единицу произведенного им ВВП, тнэ }\end{array}$ \\
\hline & $\begin{array}{l}\text { Для экспор- } \\
\text { теров }\end{array}$ & $\begin{array}{l}\text { Т5э. Относительная } \\
\text { глубина переработки } \\
\text { нефти }\end{array}$ & $\begin{array}{l}\text { Степень переработки нефти в стране, нормированная по } \\
\text { доле нефтяного сектора в энергетической системе страны }\end{array}$ \\
\hline \multirow{6}{*}{ 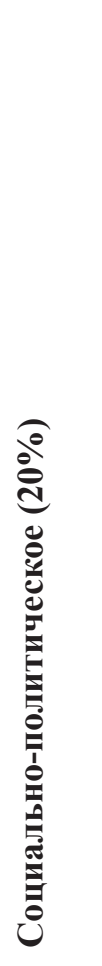 } & \multicolumn{2}{|c|}{ СП1. Доступность электроэнергии } & $\begin{array}{l}\text { Затраты на электроэнергию по отношению к уровню ВВП } \\
\text { на душу населения, взвешенные по уровню электрифика- } \\
\text { ции страны, \% }\end{array}$ \\
\hline & \multicolumn{2}{|c|}{$\begin{array}{l}\text { СП2. Современный характер энерго- } \\
\text { потребления }\end{array}$} & $\begin{array}{l}\text { Доля традиционных источников топлива (дерево и древес- } \\
\text { ный уголь, побочные продукты сельского хозяйства и др.) } \\
\text { по отношению к общему энергопотреблению населения, \% }\end{array}$ \\
\hline & \multicolumn{2}{|c|}{$\begin{array}{l}\text { СПЗ. Эффективность политической } \\
\text { системы }\end{array}$} & $\begin{array}{l}\text { Средняя оценка показателей Качества государственного } \\
\text { регулирования, предложенных Всемирным Банком (по- } \\
\text { литическая стабильность, качество законодательной и ис- } \\
\text { полнительной систем) }\end{array}$ \\
\hline & \multicolumn{2}{|c|}{$\begin{array}{l}\text { СП4. Эффективность социальной } \\
\text { системы }\end{array}$} & $\begin{array}{l}\text { Средняя оценка показателей контроля над коррупцией и } \\
\text { качества судебной власти, предложенных Всемирным Бан- } \\
\text { ком, взвешенных по уровню макроэкономической стабиль- } \\
\text { ности, используемого Всемирным экономическим форумом }\end{array}$ \\
\hline & \multicolumn{2}{|c|}{$\begin{array}{l}\text { СП5. Доступность топлива для на- } \\
\text { селения }\end{array}$} & $\begin{array}{l}\text { Средняя розничная стоимость автомобильного топлива, } \\
\text { взвешенная по уровню ВВП на душу населения }\end{array}$ \\
\hline & $\begin{array}{l}\text { Для импор- } \\
\text { теров }\end{array}$ & $\begin{array}{l}\text { СПби. Стратегическая } \\
\text { стабильность энерго- } \\
\text { системы }\end{array}$ & $\begin{array}{l}\text { Отношение суммы стратегических резервов и запасов ис- } \\
\text { копаемых энергоресурсов к объему ежеднедневной пере- } \\
\text { работки, дней }\end{array}$ \\
\hline \multirow{4}{*}{ 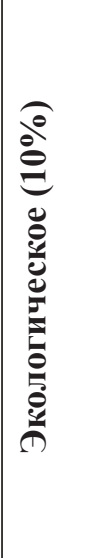 } & \multicolumn{2}{|c|}{$\begin{array}{l}\text { Э1. Эмиссионная интенсивность на } \\
\text { душу населения }\end{array}$} & $\begin{array}{l}\text { Тонн связанных с энергетической системой эмиссий ди- } \\
\text { оксида углерода на душу населения, кг } \mathrm{CO}_{2} /\end{array}$ \\
\hline & \multicolumn{2}{|c|}{$\begin{array}{l}\text { Э2. Эмиссионная интенсивность по- } \\
\text { требления энергии }\end{array}$} & $\begin{array}{l}\text { Тонн связанных с энергетической системой эмиссий диок- } \\
\text { сида углерода на единицу потребленной в стране энергии, } \\
\text { кг } \mathrm{CO}_{2} / \text { млн тнэ }\end{array}$ \\
\hline & $\begin{array}{l}\text { Для экспор- } \\
\text { теров }\end{array}$ & $\begin{array}{l}\text { Э3э. Эмиссионная на- } \\
\text { сыщенность энергети- } \\
\text { ческого экспорта }\end{array}$ & $\begin{array}{l}\text { Дополнительная эмиссия парниковых газов, приходящая- } \\
\text { ся на экспортируемые источники энергии, кг } \mathrm{CO}_{2} / \mathrm{MлH} \text { тнэ }\end{array}$ \\
\hline & $\begin{array}{l}\text { Для импор- } \\
\text { теров }\end{array}$ & $\begin{array}{l}\text { Э3и. Распределен- } \\
\text { ность энергопотребле- } \\
\text { ния }\end{array}$ & Доля возобновляемой энергии в ПЭ, \% \\
\hline
\end{tabular}


Сопоставительный анализ предлагаемого здесь и рассмотренных выше количественных подходов к определению ЭнБ представлен в таблице 2. Важно отметить необходимость учитывать качество государственного регулирования и политические риски энергетической системы.

Таблица 2. Сравнение основных количественных способов оценки ЭнБ

\begin{tabular}{|c|c|c|c|c|}
\hline $\begin{array}{l}\text { Аналитиче- } \\
\text { ский } \\
\text { критерий }\end{array}$ & КОМЭБ & $\begin{array}{l}\text { Отдельные индика- } \\
\text { торы ЭнБ }\end{array}$ & $\begin{array}{l}\text { Индекс энергетиче- } \\
\text { ской устойчивости } \\
\text { МИРЭС }\end{array}$ & Индекс рисков ЭнБ \\
\hline $\begin{array}{l}\text { Исходные } \\
\text { данные }\end{array}$ & $\begin{array}{l}\text { Данные, публикуемые } \\
\text { правительственными } \\
\text { структурами и между- } \\
\text { народными организа- } \\
\text { циями, на определен- } \\
\text { ную дату }\end{array}$ & $\begin{array}{l}\text { Данные, публикуе- } \\
\text { мые правительствен- } \\
\text { ными структурами } \\
\text { и международными } \\
\text { организациями на } \\
\text { дату или за период, } \\
\text { кроме того, могут } \\
\text { использоваться } \\
\text { данные частных не- } \\
\text { государственных } \\
\text { структур, как Free- } \\
\text { dom House или PRS } \\
\text { Group }\end{array}$ & $\begin{array}{l}\text { Данные, публикуе- } \\
\text { мые правительствен- } \\
\text { ными структурами } \\
\text { и международными } \\
\text { организациями, вре- } \\
\text { менные ряды или на } \\
\text { определенную дату }\end{array}$ & $\begin{array}{l}\text { Временные ряды дан- } \\
\text { ных, публикуемых } \\
\text { правительственными } \\
\text { структурами (в ос- } \\
\text { новном, Агентством } \\
\text { энергетической ин- } \\
\text { формации США) и } \\
\text { международными } \\
\text { организациями, на } \\
\text { определенную дату. } \\
\text { Для оценки полити- } \\
\text { ческих рисков ис- } \\
\text { пользуется рейтинг } \\
\text { Freedom Ноuse }\end{array}$ \\
\hline Методология & $\begin{array}{l}\text { • Простой подсчет } \\
\text { значений отдельных } \\
\text { индикаторов } \\
\text { • Каждый индикатор } \\
\text { нормируется по } \\
\text { шкале от } 1 \text { до } 100 \\
\text { (максимум) по от- } \\
\text { ношению к лучшему } \\
\text { значению конкретно- } \\
\text { го индикатора } \\
\text { • Отдельно разрабо- } \\
\text { танные индикаторы } \\
\text { для экспортеров и } \\
\text { импортеров энерге- } \\
\text { тических ресурсов } \\
\text { • Сумма оценок ин- } \\
\text { дикаторов в опреде- } \\
\text { ленном измерении, } \\
\text { с учетом заданного } \\
\text { в соответствии с за- } \\
\text { дачами исследования } \\
\text { веса измерений, дает } \\
\text { единую общую оцен- } \\
\text { ку индекса }\end{array}$ & $\begin{array}{l}\text { • Подсчет значений } \\
\text { отдельных индика- } \\
\text { торов может быть } \\
\text { как простым, так и } \\
\text { непрозрачным и за- } \\
\text { трудненным, напр. } \\
\text { В индексах Нефтя- } \\
\text { ной уязвимости, } \\
\text { индексе Спроса/ } \\
\text { Предложения и др. } \\
\text { • Некоторые индика- } \\
\text { торы требуют эко- } \\
\text { номического или } \\
\text { эконометрического } \\
\text { моделирования и } \\
\text { прогнозирования с } \\
\text { помощью сложных } \\
\text { компьютерных } \\
\text { вычислений, что } \\
\text { затрудняет про- } \\
\text { зрачность и понят- } \\
\text { ность результатов } \\
\text { исследования }\end{array}$ & $\begin{array}{l}\text { • Простой подсчет } \\
\text { значений отдель- } \\
\text { ных индикаторов, } \\
\text { некоторые исполь- } \\
\text { зуются из статисти- } \\
\text { ческих данных без } \\
\text { изменений } \\
\text { - Каждый индикатор } \\
\text { нормируется по } \\
\text { шкале от } 1 \text { до } 10 \\
\text { (максимум) по от- } \\
\text { ношению к стране с } \\
\text { лучшим значением } \\
\text { конкретного инди- } \\
\text { катора } \\
\text { Сумма оценок ин- } \\
\text { дикаторов в опреде- } \\
\text { ленном измерении, } \\
\text { с учетом заданного } \\
\text { экспертами веса из- } \\
\text { мерений, дает еди- } \\
\text { ную общую оценку } \\
\text { индекса }\end{array}$ & $\begin{array}{c}\text { • Подсчет значений } \\
\text { отдельных индика- } \\
\text { торов непрозрачен } \\
\text { • Значение каждого } \\
\text { индикатора срав- } \\
\text { нивается со сред- } \\
\text { ним показателем } \\
\text { в странах ОЭСР в } \\
1980 \text { году. Нормиро- } \\
\text { ванные индикаторы } \\
\text { принимают значе- } \\
\text { ния в обе стороны } \\
\text { от 1000. Чем ниже } \\
\text { значение индикато- } \\
\text { ра, тем лучше со- } \\
\text { стояние ЭнБ } \\
\text { Сумма значений } \\
\text { индикаторов, с } \\
\text { учетом заданного } \\
\text { экспертами веса ин- } \\
\text { дикаторов, дает еди- } \\
\text { ную общую оценку } \\
\text { индекса }\end{array}$ \\
\hline
\end{tabular}




\begin{tabular}{|c|c|c|c|c|}
\hline $\begin{array}{l}\text { Особенности } \\
\text { анализа }\end{array}$ & $\begin{array}{l}\text { •КОМЭБ дает целост- } \\
\text { ное представление } \\
\text { основных измерений } \\
\text { ЭнБ страны: Эконо- } \\
\text { мического, Техноло- } \\
\text { гического, Социаль- } \\
\text { но-политического и } \\
\text { Экологического } \\
\text { •Полученная оценка } \\
\text { индекса позволяет } \\
\text { сравнить качество } \\
\text { государственной } \\
\text { энергетической } \\
\text { политики стран, } \\
\text { находящихся в сопо- } \\
\text { ставимом положении } \\
\text { в мировой энергети- } \\
\text { ческой системе } \\
\text { •Для оценки качества } \\
\text { государственной } \\
\text { политики исполь- } \\
\text { зуются данные } \\
\text { Всемирного Банка и } \\
\text { Всемирного эконо- } \\
\text { мического форума }\end{array}$ & $\begin{array}{l}\text { • Каждый индика- } \\
\text { тор характеризует } \\
\text { отдельный эле- } \\
\text { мент или сектор } \\
\text { энергетической } \\
\text { системы, в основ- } \\
\text { ном экономиче- } \\
\text { ское измерение } \\
\text { • Для более полного } \\
\text { анализа требуется } \\
\text { использовать не- } \\
\text { сколько индикато- } \\
\text { ров } \\
\text { • Нельзя получить } \\
\text { полное представле- } \\
\text { ние об обеспечении } \\
\text { ЭнБ }\end{array}$ & $\begin{array}{l}\text { • Индекс дает це- } \\
\text { лостное представ- } \\
\text { Энье измерений Социальной } \\
\text { справедливости, } \\
\text { Воздействия на } \\
\text { окружающую } \\
\text { среду и Качества } \\
\text { государственного } \\
\text { управления и соци- } \\
\text { ально-экономиче- } \\
\text { ской структуры } \\
\text { • Полученная оценка } \\
\text { индекса позволяет } \\
\text { сравнить страны, } \\
\text { находящиеся в од- } \\
\text { ном кластере миро- } \\
\text { вой экономической } \\
\text { системы } \\
\text { • Для оценки каче- } \\
\text { ства государствен- } \\
\text { ной политики ис- } \\
\text { пользуются данные } \\
\text { Всемирного Банка } \\
\text { и Всемирного } \\
\text { экономического } \\
\text { форума }\end{array}$ & $\begin{array}{l}\text { • Индикатор призван } \\
\text { показать риски ЭнБ } \\
\text { страны и их динами- } \\
\text { ку за период } \\
\text { • } 36 \% \text { общей оцен- } \\
\text { ки ЭнБ страны } \\
\text { приходятся на не } \\
\text { зависящие от на- } \\
\text { циональной энерге- } \\
\text { тической политики } \\
\text { обстоятельства } \\
\text { мирового рынка } \\
\text { энергоресурсов (на- } \\
\text { пример, динамику и } \\
\text { волатильность цен } \\
\text { на нефть на мировых } \\
\text { рынках) } \\
\text { • Для оценки полити- } \\
\text { ческого измерения } \\
\text { используется рей- } \\
\text { тинг политических } \\
\text { прав и гражданских } \\
\text { свобод Ғгеедот } \\
\text { Ночее }\end{array}$ \\
\hline Применение & $\begin{array}{l}\text { КОМЭБ позволяет } \\
\text { сравнить уровни ЭнБ } \\
\text { в разных странах } \\
\text { и модифицировать } \\
\text { энергетические стра- } \\
\text { тегии. Анализ каче- } \\
\text { ства мер по обеспече- } \\
\text { нию ЭнБ. Облегчение } \\
\text { условий регионально- } \\
\text { го и международного } \\
\text { энергетического со- } \\
\text { трудничества и коопе- } \\
\text { рации. }\end{array}$ & $\begin{array}{l}\text { Например, для оцен- } \\
\text { ки энергетического } \\
\text { импорта может ис- } \\
\text { пользоваться Индекс } \\
\text { зависимости от им- } \\
\text { порта энергоресур- } \\
\text { сов. Если исследует- } \\
\text { ся международный } \\
\text { нефтяной рынок, } \\
\text { может использовать- } \\
\text { ся Индекс нефтяной } \\
\text { уязвимости и т. д. }\end{array}$ & $\begin{array}{l}\text { ИЭУ позволяет со- } \\
\text { поставить качество } \\
\text { энергетической и } \\
\text { экологической по- } \\
\text { литики государств к } \\
\text { конкретном году }\end{array}$ & $\begin{array}{l}\text { Сравнение рисков } \\
\text { ЭнБ отдельных стран } \\
\text { и групп государств во } \\
\text { времени. Полезен для } \\
\text { исторического анали- } \\
\text { за ЭнБ благодаря ис- } \\
\text { пользованию длинных } \\
\text { временных рядов }\end{array}$ \\
\hline
\end{tabular}

Согласно обоснованному предположению Ивана Егорова-Тисменко ${ }^{20}$, внешняя политика государств зависит от принадлежности страны к классу, определенному в соответствии с уровнем его энергообеспе-

${ }^{20}$ Егоров-Тисменко И.Ю. Территориальная структура мировой нефтяной промышленности в системе международных отношений: дис. ... канд. геогр. наук. - М., 2007. ченности и геополитического влияния. Внутренняя и внешняя энергетическая политика страны зависит от того, является ли страна импортером или экспортером энергоресурсов, а также от того, насколько важным геополитическим центром она является. Очевидно, что и к анализу энергетической политики государств следует подходить, учитывая их специализацию в мировой энергетической системе. Степень геополи- 
тической значимости страны объективно оценить не представляется возможным, однако ее вполне (как, в частности, показывает пример подхода МИРЭС) можно вывести из объективных макроэкономических показателей и индикаторов институционального развития. При этом совершенно неприемлемым кажется применение сомнительных по объективности разработок частных исследовательских структур, наподобие рейтингов, публикуемых организацией Freedom House, или страновых рейтингов крупных консалтинговых компаний (PRS Group, S\&P, Moody's и других), публикуемых по закрытой методике и оценивающих риски, малозначимые при анализе национальной энергетической политики.

Кроме того, уровень безопасности государств в мировой нефтяной промышленности (здесь можно перейти на более высокий уровень обобщения, говоря в целом о положении страны в мировой энергетической системе) изменяется в зависимости от развития и значимости национальных экономик на международном уровне, а также от того, импортирует, экспортирует ли конкретная страна значимые объемы энергоресурсов или занимает важное место в качестве транзитного государства. Расположение государств в данном пространстве координат характеризуется разным состоянием критериев энергетической безопасности, что требует проведения подчас значительно различающейся энергетической политики. Соответственно, к анализу эффективности такой политики следует подходить, учитывая эти особенности. Именно поэтому КОМЭБ осуществляется для государств, находящихся в сходных с точки зрения макроэкономики и роли в энергетической системе условиях.

Дискуссии в области ЭнБ пересекаются вплоть до смешения с вопросами стратегии государственной энергетической политики. Такие эксперты, как Майкл Леви, видят оптимальную стратегию развития энергетики в увеличении производства как конвенциональных источников энергии, так и возобновляемых, с государственным стимулированием более энергоэффективных технологий, не увеличивающих привязку экономики к нефти ${ }^{21}$. Подобное видение энергетической политики уже имплицитно заключает в себе определенное представление обеспечения ЭнБ страны, максимизацию вклада энергетического сектора страны

${ }^{21}$ Levi, M. America's energy opportunity. Foreign Affairs. - 2013, 3 апреля. в социально-экономическое развитие с помощью государственной энергетической политики. Представленная в работе методика расчета комплексной оценки международной энергетической безопасности позволяет оценить успешность осуществления подобной политики.

\section{Библиография:}

1. Егоров-Тисменко И.Ю. Территориальная структура мировой нефтяной промышленности в системе международных отношений: дис. ... канд. геогр. наук. -М., 2007;

2. Латухина К. Во глубине ямальских недр // Российская газета. - 2012, 24 октября;

3. Alhajji, A.F. The meaning of energy security. Блог USAEE, - 2006, 22 августа;

4. Blyth W., Lefevre N. Energy security and climate change policy interactions: an assessment framework. International Energy Agency (IEA), 2004;

5. Chester L. Conceptualizing energy security and making explicit its polysemic nature. Energy Policy, 38, 2010, pp. 887-895;

6. International Atomic Energy Agency. Energy indicators for sustainable development: guidelines and methodologies. IAEA, Vienna, 2005;

7. International Energy Agency. Energy security and climate policy assessing, interactions. IEA, Paris, 2007;

8. Keohane, R.O., Nye, J.S. Power and interdependence. Longman, New York, 2001;

9. Knox-Hayes, J. et al. Understanding attitudes toward energy security: results of a cross-national survey. Global Environmental Change, 23, 2013;

10. Levi, M. America's energy opportunity. Foreign Affairs. - 2013, 3 апреля;

11. Loschel, A., Moslener, U., Rubbelke, D. Indicators of energy security in industrialized countries. Energy Policy, 37, 2009;

12. Martchamadol J, Kumar S. An aggregated energy security performance indicator. Applied Energy, vol. 103, 2013, pp. 653-670;

13. Shin, J. et al. An energy security management model using quality function deployment and system dynamics. Energy Policy, 2012;

14. Sorman A.H., Giampietro M. Generating better energy indicators: addressing the existence of multiple scales and multiple dimensions. Ecological Modelling, 223, 2011; 
DOI: $10.7256 / 2073-8560.2013 .4 .8897$

При цитировании этой статьи сноска на doi обязательна

\section{Национальная безопасность $4(27) \cdot 2013$}

15. Sovacool, B.K. An international assessment of energy security performance. Ecological Economics, 88, 2013;

16. Vivoda V. Evaluating energy security in the AsiaPacific region: a novel methodological approach, Energy Policy, 38, 2010;

17. Von Hippel, D. et al. Energy security and sustainability in Northeast Asia. Energy Policy, 1-12, 2009;

18. World Energy Council. World energy trilemma. Energy sustainability index. WEC, London, 2012.

\section{References (transliteration):}

1. Egorov-Tismenko I.Yu. Territorial'naya struktura mirovoy neftyanoy promyshlennosti v sisteme mezhdunarodnyh otnosheniy: dis. ... kand. geogr. nauk. - M., 2007;

2. Latuhina K. Vo glubine yamal'skih nedr // Rossiyskaya gazeta. - 2012, 24 oktyabrya;

3. Alhajji, A.F. The meaning of energy security. Blog USAEE, - 2006, 22 avgusta;

4. Blyth W., Lefevre N. Energy security and climate change policy interactions: an assessment framework. International Energy Agency (IEA), 2004;

5. Chester L. Conceptualizing energy security and making explicit its polysemic nature. Energy Policy, 38, 2010, pp. 887-895;

6. Keohane, R.O., Nye, J.S. Power and interdependence. Longman, New York, 2001;

7. Knox-Hayes, J. et al. Understanding attitudes toward energy security: results of a cross-national survey. Global Environmental Change, 23, 2013;

8. Levi, M. America's energy opportunity. Foreign Affairs. - 2013, 3 aprelya;

9. Loschel, A., Moslener, U., Rubbelke, D. Indicators of energy security in industrialized countries. Energy Policy, 37, 2009;

10. Martchamadol J, Kumar S. An aggregated energy security performance indicator. Applied Energy, vol. 103, 2013, pp. 653-670;

11. Shin, J. et al. An energy security management model using quality function deployment and system dynamics. Energy Policy, 2012;

12. Sorman A.H., Giampietro M. Generating better energy indicators: addressing the existence of multiple scales and multiple dimensions. Ecological Modelling, 223, 2011;

13. Sovacool, B.K. An international assessment of energy security performance. Ecological Economics, 88, 2013;

14. Vivoda V. Evaluating energy security in the AsiaPacific region: a novel methodological approach, Energy Policy, 38, 2010;

15. Von Hippel, D. et al. Energy security and sustainability in Northeast Asia. Energy Policy, 1-12, 2009; 